\title{
Memoria de trabajo y comprensión lectora en estudiantes de una institución educativa estatal
}

\author{
Working memory and reading comprehension in students of a state educational institution \\ Cecilia Patricia Castro Chávarry 1,a,b \\ RESUMEN
}

El objetivo de la presente investigación es encontrar la relación entre la memoria de trabajo (MT) y la comprensión lectora (CL) en niños de 10 y 11 años de edad pertenecientes a un colegio estatal de Chorrillos en la ciudad de Lima (Perú). Se aplicaron dos instrumentos: la Prueba de Amplitud Lectora PAL-N para niños de Carriedo \& Rucián y la Prueba de Comprensión Lectora de Complejidad Lingüística de Alliende, Condemarín y Milicic. La muestra estuvo conformada por 120 niñas y niños de los cuales 60 fueron de 10 años de edad y 60 de 11 años. Los resultados mostraron una correlación significativa entre la MT y CL, caracterizándose por ser baja y positiva. Asimismo, se encontró relación entre la MT y CL en los participantes de 11 años, más no en los participantes de 10 años. Finalmente, los resultados mostraron diferencias significativas en la CL entre los participantes de 10 y 11 años de edad, pero no se evidenció diferencias significativas en la MT entre dichos grupos.

PALABRAS CLAVE: Comprensión lectora, escolares, memoria de trabajo.

\section{SUMMARY}

The objective of this research is to find the relationship between working memory (WM) and reading comprehension (RC) in children from 10 to 11 years old in a state school from Chorrillos (Lima, Peru). In the research two instruments were applied: Reading Span Test PAL-N, by Carriedo \& Rucián, and the Reading Comprehension Test of linguistic complexity by Alliende, Condemarín and Milicic. The sample consisted in 120 children, 60 children were 10 years old and the other 60 children were 11 years old. The results showed a low, but significant positive correlation between WM and RC. Likewise, relationship between WM and RC in participants that were 11 years old, but not in those 10 years old ones was found. Finally, it was found significant differences in RC among participants of 10 and 11 years old, but has not found significant differences in WM Memory between these groups.

KEYWORDS: elementary school students, reading comprehension, working memory

\section{INTRODUCCIÓN}

\section{Memoria de Trabajo}

El modelo modal de la memoria, planteado por Atkinson y Shiffrin en 1968 (Hulme \& Mackenzie,
1994), también conocido como modelo de procesamiento de la información (Bruning, Schraw, Norby \& Ronning, 2007) representa la memoria en términos de tres estructuras. La primera estructura denominada Memoria Sensorial (MS) está encargada de recibir las primeras informaciones que ingresan vía

\footnotetext{
Facultad de Psicología, Universidad Femenina del Sagrado Corazón. Lima, Perú.

a Magíster en Psicología con mención en Psicología Educativa y Problemas de Aprendizaje

b ORCID: 0000-0001-7324-5701
} 
sensorial, información que se quedaría almacenada por aproximadamente cien milisegundos (Smith, 2008), para luego pasar a la segunda estructura denominada Memoria a Corto Plazo (MCP). La MS tiene funciones específicas de análisis perceptual el cual posibilita asociar la información perceptual con un patrón reconocible (Bruning et al., 2007). Cuando la información pasa a la MCP, se aloja allí durante unos segundos para dar inicio a un segundo procesamiento y dependiendo de la relevancia que se le dé, pasará a la Memoria de Largo plazo (MLP). Finalmente, la MLP sería como el gran almacén permanente, en la cual se encontraría una gran cantidad de información producto de toda experiencia a la cual el ser humano fue expuesto durante toda su vida. Aquí se encontrarían codificados recuerdos, personas, lugares, objetos, situaciones y acciones como el manejar una bicicleta. En general la información retenida en la MLP vendría a constituir los conocimientos, aquellos que en determinado momento requerirán ser evocados para satisfacer un requerimiento cognitivo o procedimental. Toda esta información enviada a la MLP se almacenaría gracias a un proceso que se da en la memoria caracterizada por la repetición y además, la información ya almacenada podría ser recuperada gracias a la MCP. Lo resaltante de este modelo es la definición de tres estructuras que además de tener funciones claramente establecidas, permitirían esbozar el concepto de "ideas previas", que serían la información procesada y retenida sistemáticamente en MLP, la misma que sería vital para la formación de nuevos conocimientos (Bruning et al., 2007).

Las críticas recibidas por este modelo estuvieron referidas a lo lineal que se presentaba el paso de la información de una estructura a otra, percibiéndose a la memoria como una serie de estructuras separadas entre sí y que no explicaría del todo cómo funcionaría cada estructura cuando se está procesando información. Esto condujo a los investigadores a plantear un enfoque diferente que incluyera la acción del procesamiento de la información, analizándola como un proceso activo y permanente. Se da entonces, mayor importancia al estudio de la MCP, a la cual se le asignaría un rol más dinámico del que inicialmente se le otorgó, con ello se hablaría no sólo de una retención breve de la información, sino de un "cómo" se manejaría la información retenida inicialmente, antes de pasar a la MLP. La MCP ya no sería considerada sólo como un puente con la MLP, sería también una estructura que se mantendría constantemente trabajando, decidiendo y regulando el tipo de información que pasará a la MLP o que recuperaría de ella.
Por ello, por su función dinámica, actualmente se ha preferido hablar ya no de MCP, en su lugar se usa los términos de Memoria Operativa o Memoria de Trabajo (MT). Esta nueva denominación refleja un proceso histórico en el cual cabe resalta el trabajo de George Miller, quien en 1956 hablaba de cierto dinamismo en la memoria al encontrar datos que demostraban la capacidad limitada de almacenamiento. Tras ciertos experimentos, logró establecer un número específico de elementos que podían ser almacenados en MCP y en 1956 publica el famoso artículo titulado "El mágico número siete, más o menos dos": las personas sólo pueden mantener unos siete "elementos activos" en el almacén de corto plazo y además emplearían estrategias para ampliar la capacidad de almacenamiento, lo cual a su vez permitiría la ejecución de una amplia gama de tareas mentales (Smith, 2008).

Los elementos activos a los que hizo referencia Miller, serían el producto de una estrategia observada en sus evaluados por la cual ellos "agrupaban" los elementos de a tres con la finalidad de retener mayor información, siendo ésta la estrategia perfecta para aumentar la capacidad de almacenamiento. Pero la estrategia de "agrupamiento" es un proceso dinámico, queimplicaría acciones previas al pasaje de información a la MLP. Efectos similares se observan cuando lo que incrementa no es la cantidad de información, sino el tiempo de retención. Por ejemplo, Prada, Pineda, Mejía y Conde (2010) evaluaron los efectos de dos intervalos de exposición de dígitos ( 1 y 8 segundos) y la presentación de un distractor sobre el desempeño de la memoria de trabajo de 80 mujeres mayores de 50 años. Se evidenció un efecto significativo del intervalo sobre las variables: número de aciertos, aciertos acumulados, y empleo de estrategias adicionales, demostrando un mejor desempeño mnemónico en participantes que presentaron la prueba en el intervalo de 8 segundos, lo que según los autores, sugiere que un tiempo amplio de exposición potencia la capacidad de almacenamiento de la memoria en adultos mayores. Asimismo, Argüello, Jácome, Martínez, Pineda, y Conde (2013) evaluaron los efectos de tres tiempos de exposición (1, 4 y 8 segundos) y de la presentación de un distractor sobre el desempeño mnemónico en niños entre 8 y 11 años, encontrándose un mejor desempeño en los participantes que presentaron la prueba en el tiempo de 8 segundos. Se halló una diferencia significativa en cuanto al uso de la estrategia de repetición mental, indicando que los participantes de los grupos de 4 y 8 segundos le asignaron mayor puntaje que los niños del grupo 1 segundo. Un amplio tiempo de exposición de estímulos aumenta la capacidad de retención. 
Posteriormente, Baddeley y Hitch (1974) desarrollaron un modelo dinámico para el estudio de la memoria, en el cual usan el término Memoria de Trabajo para referirse a la MCP del modelo de Atkinson y Shiffrin. El modelo de Baddeley plantea tres puntos importantes (Smith, 2008). En primer lugar, la función de almacenaje en MCP ya no se define como una única función pasiva, en su lugar se explica que la información almacenada se mantendría activa a través de dos procesos: procesamiento y almacenamiento, los que permitirían la ejecución de actividades cognitivas complejas como el razonamiento, el pensamiento y la escritura (García, Elosúa, Gutiérrez, Luque \& Gárate, 1999). En segundo lugar, existen dos ejes, el primero tiene una función de control llamado Ejecutivo Central (EC) y sería responsable de movilizar la información retenida en la MCP, ya sea expulsándola hacia la MLP o eliminándola para su olvido. El segundo eje estaría formado a su vez por tres estructuras de almacenamiento de la información a los que se llamaría buffers (Smith, 2008). En tercer lugar, los buffers contienen ciertas propiedades. Inicialmente el modelo planteó el funcionamiento de dos buffers; uno llamado bucle fonológico para la información verbal y otro denominado bloc de notas viso-espaciales para la información visual y espacial. Posteriormente, en el año 2000 Baddeley y Hitch agregan a su modelo inicial un tercer buffer al que denominan buffer episódico, el cual se encargaría de procesar información que no podía ser manejada por los dos buffers anteriores (Caicedo, 2012). Estas características explicarían el papel dinámico de la MT, descrita por Hulme y Mackenzie (1994) como el conjunto de sistemas responsables del almacenamiento temporal de la información que se usa cuando se está realizando una tarea cognitiva.

Dentro del modelo de Baddeley y Hitch, el EC sería la instancia primordial, ya que determinaría cómo se emplean los recursos cognitivos y como se suprimiría la información improcedente que podría interferir en sí en el proceso de la MT. Sería como el director de una orquesta cuyas funciones serían: a) determinar cuándo la información se guarda en los buffers de almacenamiento, b) determinar qué buffer, el bucle fonológico, viso-espacial o episódico, es seleccionado para almacenar la información, c) Integrar y coordinar la información entre los tres buffers y d) proporcionar un mecanismo mediante el cual la información que se mantiene en los buffers se pueda inspeccionar, transformar y manipular cognitivamente de cualquier otra manera (Smith, 2008). La función principal asociada al EC, sería la de control y atención, pero también estaría asociada la de comprensión del lenguaje, razonamiento y operaciones de almacenamiento y recuperación de información de la memoria a largo plazo (Fernández \& Fraga, 2004) El bucle fonológico se encargaría de almacenar y procesar toda la información verbal a la que están expuestas las personas. La información puede ser presentada de manera visual, por ejemplo cuando se lee, y también puede ser presentada de manera oral cuando se mantiene una conversación por ejemplo; en ambos casos la información verbal es procesada por el bucle fonológico pero la ruta que sigue para procesarla es diferente.

Cuando la información es presentada de manera visual, primero es trasformada en códigos fonológicos por medio de un componente del buffer llamado almacén fonológico y se mantiene en él gracias a la acción de un segundo componente llamado ensayo articulatorio, por el cual se pronuncia mentalmente el código reverberándose automáticamente hasta quedar fijo en el almacén fonológico por un tiempo limitado pero suficiente como para ser usado (Smith, 2008). Pero cuando la información es presentada de manera auditiva la información accede de manera directa al almacén fonológico independientemente de si está utilizando o no el ensayo articulatorio (Fernández \& Fraga, 2004).

Por otro lado, en el bucle fonológico se dan tres efectos que serían responsables de afectar el funcionamiento de la MT. El primero de ellos es el efecto de similitud fonológica, quien afectaría el componente almacén fonológico porque las palabras con similitud de sonido serían más difíciles de retener. El otro efecto está referido a la amplitud de la palabra, es decir cuando más grande sea la palabra o esté conformada por mayor cantidad de sílabas por articular, se generaría un declive en la cantidad de elementos retenidos, con ello mientras más extensa sean las palabras a retenerse, menor serán el número de elementos almacenados. El tercer efecto es denominado supresión articulatoria, por la cual el componente del control articulatorio se ve interrumpido por la interferencia de estímulos ajenos a la información inicial, anula la posibilidad de repaso y la información que inicialmente estaba ingresando a memoria de trabajo se pierde parcial o totalmente.

La función del bucle fonológico estaría asociada al aprendizaje de la lectura, la comprensión del lenguaje y la adquisición de vocabulario (Fernández \& Fraga, 2004), y por ello la alteración en su 
funcionamiento impediría básicamente el desarrollo de funciones cognitivas como la comprensión (Hulme \& Mackenzie, 1994). Lo anterior pudo observarse en diversos estudios sobre niños y adultos con dificultades graves en el aprendizaje y/o víctimas de accidentes cerebrovasculares los que se describirán posteriormente.

La información visual retenida, no sería procesada sólo a nivel fonológico, que implicaría un canal y procesamiento auditivo-visual, tendría además que pasar por un proceso visual-espacial, el cual se desarrollaría en el buffer bloc de notas viso-espacial donde la información adquiriría mayor significado. Este buffer sería el responsable de elaborar y manipular imágenes visuales, permitiendo un desplazamiento mental que posibilitaría ejecutar tareas de orientación geográfica y/o la planificación de tareas espaciales (Caicedo, 2012).

Finalmente, el buffer episódico se encargaría de atender la información que no puede ser procesada por los dos anteriores (fonológico y viso-espacial). El buffer episódico explicaría el fenómeno de "agrupamiento" descrito por Miller en 1956, por lo cual al unir información entre sí, la capacidad de amplitud en la memoria se vería beneficiada. La principal función del episódico es ser auxiliar de los otros buffers, pero además se encarga de almacenar por breves instantes sucesos y episodios necesarios para dar sentido a la información que se está procesando, permitiendo además, integrar la información con los otros buffers y la MLP (Inga, 2008).

\section{Procesos de la Comprensión Lectora y la Memoria de Trabajo}

La lectura es el proceso basado en el lenguaje y que incluye la construcción de significados a partir de un texto (Brunning et al., 2007). Comprender, según García et al. (1999) es un proceso interactivo que implica la construcción de una representación mental acerca del significado global del discurso. Tres factores cognitivos garantizarían el éxito en la lectura: a) El conocimiento de la palabra, (2) la capacidad de la MT y la MLP y (3) la habilidad para centrar la atención. De esta manera, la comprensión lectora (CL) implica diversos procesos que al estar articulados entre sí determinarían un complejo sistema cognitivo que permitiría seguir una historia, contestar interrogantes o dar una opinión relacionada a lo que se está leyendo. Un conocido modelo que describe el proceso de $\mathrm{CL}$ es el propuesto por Gough, quien planteó que la información contenida en el texto viaja desde el reconocimiento visual de las letras o grafemas, hasta el procesamiento semántico del texto como un todo, sin que la relación inversa sea necesaria (Alonso, 1992). En contraposición a este modelo, Goodman en 1976, planteó que los buenos lectores seguirían una ruta inversa al modelo anterior, es decir habría un proceso descendente, del procesamiento que se da en la mente del lector al texto. Por ello, lo primero que sucedería en un buen lector sería la construcción de un significado, el cual daría origen a más predicciones futuras del significado en base al texto que se está leyendo. Cuando la nueva predicción formada se cumple, la lectura fluiría, se enriquecería el significado inicial y se generaría comprensión de lo que se lee. En caso contrario, si la predicción no se cumple, el lector bajaría su velocidad de lectura para volver a releer el significado construido, buscaría nuevos significados para asociarlo, formaría nuevas predicciones y se retornaría al ritmo de la lectura (Brunning et al., 2007, Gómez-Veiga, Vila, García Madruga, Contreras y Elosúa, 2013).

Otro modelo de la CL, y quizá el de mayor influencia, fue propuesto por Walter Kintsch (Kintsch y van Dijk, 1978), denominado modelo construcciónintegración. Este modelo planteó el análisis de la comprensión lectora a partir de la comprensión de frases. En este caso, el lector procesa el texto en ciclos, para ello formaría ideas elementales o proposiciones a partir de las expresiones del texto y luego las conecta unas con otras. De este modo, una idea podría activar otra idea, y está a otra de tal modo que todas las ideas interconectadas entre sí construirían un maya de información, la que permitirían comprender un todo. Además de la activación de ideas, el modelo plantea otros conceptos como las macroproposiciones e inferencias-puente; el primero permitiría consolidar una idea-concepto, mientras que el segundo permitiría al lector generar una idea de conexión entre dos ideas aparentemente aisladas (Miranda, Vidal-Abarca \& Soriano, 2011).

Lo anterior se encuentra relacionado con lo descrito por García et al. (1999), quienes le dan al lector un papel de constructor de significados porque formarían microestructuras (ideas básicas del texto) y una macroetructura (significado total del texto), que en su conjunto estaría vinculado a las macroproposiciones antes descritas. Dichos autores además explican la existencia de macrorreglas, o procesos de inferencia, que serían las responsables de generar los puentes entre una y otra idea a través de los procesos de selección 
que permitirían eliminar información secundaria y redundante y la generalización que permitiría sustituir ciertos conceptos o frases del texto por otra proposiciones supraordenadas.

La construcción de ideas conectadas unas a otras por macroproposiciones y puentes de inferencias se asemejaría a una red, la cual está integrándose y reorganizándose constantemente. Según Kintsch, ello implicaría suprimir información no pertinente y reducir la red a un conjunto coherente de proposiciones que generarían una representación mental inteligente, o como García et al, sugieren se selecciona y generaliza la información que se lee. Esta representación requeriría de un espacio mental para formarse y reformarse en la medida que la tarea cognitiva así lo demande, ya que mientras la información termina de consolidarse como macroproposiciones debe pasar a un espacio temporal que le permita estar lo suficientemente cerca para poder conectarse con otra idea y generar así inferencias, hipótesis y respuestas para finalmente comprender.

Los modelos que actualmente se consideran de construcción-integración describen también el procesamiento activo del análisis de la oración y determinan a una instancia de la MCP como responsable de este procesamiento activo ya que en ella circula la información que ha de ser almacenada o no. En tal sentido, se hablaría del rol dinámico requerido para comprender y que se llevaría a cabo dentro de la limitada capacidad de la MT (Brunning et al., 2007).

A partir de estos planteamientos se realizaron diversos estudios en torno a la MT y la CL, uno de los más importantes fue el desarrollado por Daneman y Carpenter (1980), quienes realizaron experimentos que demostraron la alta relación existente entre ambas; además, obtuvieron numerosas evidencias que abrieron rutas para poder evaluar la MT en función de la CL. Producto de ello publican el Reading Span Test, el cual fue adaptado y traducido por otros investigadores para seguir realizando nuevos estudios relacionados a la memoria, la CL y otros procesos cognitivos (Daneman y Carpenter, 1980). A este estudio le siguieron otros más, como los realizados por Hulme en 1988 (Hulme y Mackenzie, 1994), quien también encontró relación entre la MT y la CL en niños comprendidos entre los siete y los diez años, además encontró correlación entre la amplitud de la memoria y la capacidad de lectura.
Estudios similares han sido realizados en poblaciones hispanoparlantes. Fernández y GarcíaMadruga (2008) investigaron la relación entre MT, CL y razonamiento en 53 alumnos de educación secundaria en Madrid. Emplearon la prueba de Amplitud Lectora de Elosúa, Gutiérrez, García-Madruga, Luque y Gárate (1996), versión española del Reading Span Test de Daneman y Carpenter, el test de Estrategias de Comprensión de Vidal-Abarca, Gilabert, Sellés, Abad y Ferrer, y una prueba de razonamiento proposicional que incluyó dos enunciados condicionales y una disyunción incluyente. Se estudió también la capacidad predictiva de estas tres variables con respecto al rendimiento académico, obtenido a partir de las calificaciones finales de los sujetos en diversas materiales. Los resultados mostraron un patrón de correlaciones significativas entre las tres medidas, así como ente ellas y el rendimiento académico de los estudiantes.

En el Perú, Pérez (2013) investigó la relación entre la MT y el lenguaje comprensivo en niños de edad escolar. La muestra estuvo conformada por 67 niños de una escuela primaria turno mañana y tarde en una escuela pública. Se evaluaron los tres componentes de la MT: Bucle fonológico, agenda viso espacial y ejecutivo central y dos dimensiones del lenguaje comprensivo: lenguaje oral y lectura. Los resultados mostraron correlación directa, moderada y significativa entre la memoria de trabajo y lenguaje comprensivo $(r=.476, p=.006)$. Yaringaño (2009) aplicó a 228 alumnos de quinto y sexto de primaria el Test de Memoria Auditiva Inmediata y la Prueba de Complejidad Lingüística Progresiva, con el objetivo de conocer los niveles de memoria auditiva inmediata y CL. Los resultados indicaron una correlación moderada $(\mathrm{Rho}=.430)$ entre la CL y la memoria auditiva inmediata. El presente estudio se propone confirmar estos resultados en una muestra de mayor tamaño y mediante el uso de una combinación distinta de algunos de los instrumentos utilizados en los estudios antes citados.

\section{MATERIAL Y METODOS}

\section{Participantes.}

Los participantes fueron 120 niñas/os comprendidos entre los 10 y 11 años de edad de un centro educativo estatal. El método de muestreo utilizado fue no probabilístico debido a que la elección de los elementos no dependió de la probabilidad o el 
azar (Sánchez y Reyes, 1990). La distribución de la muestra según edad y sexo se presenta en la tabla 1.

Tabla 1. Distribución de la muestra según edad

\begin{tabular}{cccc}
\multicolumn{3}{c}{ y sexo } \\
\hline Edad & \multicolumn{2}{c}{ Sexo } \\
& & Niñas & Niños \\
\hline 10 & $\mathrm{~F}$ & 28 & 32 \\
& $\%$ & 46,7 & 53,3 \\
\multirow{4}{*}{11} & $\mathrm{~F}$ & 26 & 34 \\
& $\%$ & 43,3 & 56,7 \\
Total & $\mathrm{F}$ & 54 & 66 \\
& $\%$ & 45,0 & 55,0 \\
\hline
\end{tabular}

\section{Instrumentos y procedimiento.}

Prueba de Amplitud Lectora para niños (PAL-N). Fue propuesta originalmente por Daneman y Carpenter (1980) para una población de adultos y como una alternativa a las medidas clásicas de MCP. Sus reactivos son de tal naturaleza que activarían los componentes de procesamiento (representado por un conjunto de frases no relacionadas entre sí) y almacenamiento (representado por el recuerdo de la última palabra de cada frase); ambos componentes propios de las demandas normales de la comprensión lectora. La versión original en inglés, fue adaptada por Elosúa, Gutiérrez, García, Luque y Gárate (1996) España, guardando la misma naturaleza y estructura de sus reactivos. La edad de aplicación también fue para adultos. En el año 2009, Nuria Carriedo y Mercedes Rucián realizaron una adaptación de la versión de 1996 para utilizarla en una población de niños comprendidos entre los 11 y 12 años de edad. Esta nueva versión fue denominada PAL-N y es la que se empleó en la presente investigación, realizándose las respectivas adaptaciones y validaciones para los participantes de este estudio.

Siguiendo el formato de la prueba original y demás adaptaciones, el test está conformado por un total de 60 frases, cada una de ellas con una longitud de no más de 10 palabras. Las frases están distribuidas en cinco niveles de dificultad (series de frases tal como figura en la evaluación). En cada nivel hay tres series de dos, tres, cuatro o cinco frases, según el nivel conformado. Así por ejemplo, el Nivel 2 tiene tres series con dos frases cada serie, es decir seis frases en total en este nivel, en el Nivel 4 hay tres series con cuatro frases cada serie, es decir 12 frases en total. La prueba ofrece además dos frases de entrenamiento antes de proceder a la evaluación en sí, con la finalidad de que el evaluado comprenda perfectamente lo que debe hacer. Las frases no guardan relación estructural o semántica entre si y mucho menos con la última palabra de cada serie a recordar. En la presente adaptación, la mayoría de las frases originales se mantuvieron igual, las modificaciones que se realizaron fueron ejecutadas con el objetivo de que resultara más familiar para los evaluados.

El participante debe leer las frases a su propio ritmo en voz alta y al final de cada serie se le pide recordar la última palabra de cada una de las frases. La cantidad de frases leídas dependerá del nivel en el que se encuentre trabajando y la evocación solicitada deberá tener un orden estrictamente serial. El recuerdo serial consiste en que el sujeto deberá evocar primero la última palabra de la primera frase, después la última palabra de la segunda frase y así sucesivamente. El número de frases en cada serie va en aumento, de manera que también es creciente el número de frases en cada serie, y el número de palabras a recordar tras la lectura. Las últimas palabras a recordar tienen todas dos o tres sílabas y son de uso relativamente frecuentes. La prueba finaliza cuando el niño falla consecutivamente en las tres series de un determinado nivel.

Este instrumento es de aplicación individual, cada frase se presenta de manera aislada en una pantalla de computador con fondo blanco. La letra usada fue Arial tamaño 12. Al terminar cada nivel aparecería una presentación en power point con el signo de interrogación (?), lo que indicaba al niño que la serie de frases había terminado y él debía repetir las palabras finales de cada oración respetando el orden serial.

Siguiendo el procedimiento realizado por Carriedo y Rucián (2009), para adaptar los reactivos a la realidad infantil en la población investigada se sometió la prueba a dos fases de evaluación. La primera fase consistió en someter los 60 ítems a un estudio piloto con niños comprendidos entre 9 años y 10 años. Posterior al trabajo con la muestra piloto, se realizó un análisis individual, reactivo por reactivo, explorándose si la frase era comprensible o no acorde al criterio infantil y se procedió a cambiar o modificar palabras. Las modificaciones fueron pocas y la prueba final estuvo conformada por 60 ítems con las mismas características a las de la prueba inicial. En una segunda fase, se sometió los ítems a criterio de expertos con la finalidad de obtener la validez de contenido de la prueba. Para ello se usó el índice de 
Lawshe, el cual arrojó un puntaje de 0,99 (TristánLópez, 2007) dándole la validez requerida.

Para la puntuación se siguió los siguientes criterios. Una repuesta fue considerada correcta cuando al menos dos de las tres series fueron acertadas y además estas palabras recordadas fueron evocadas de manera serial o en el mismo orden en que fueron presentadas. Por encima del nivel 2 a cada serie se le asignó 2 puntos si se recordaron todas las palabras en orden y 1 punto si no siguieron el orden correcto. Además ninguna de las respuestas debía iniciarse en ningún caso por la última palabra de la serie, por ello en el nivel 2 sólo se consideró una respuesta perfectamente seriada (ordenada), razón por lo cual cada serie supuso un puntaje máximo de 1 para el Nivel 2. Finalmente la puntuación total en cada serie, fue ponderada según el nivel al que corresponde, es decir se multiplicó por el nivel al que correspondía los totales.

\section{Prueba de Comprensión Lectora de Complejidad Lingüística Progresiva}

Fue creada por Felipe Alliende, Mabel Condemarín y Neva Milicic en Chile con la finalidad de medir la capacidad de lectura en las etapas correspondientes a los ocho años de educación general básica. La prueba se elaboró en dos etapas, en la primera etapa, desarrollada en 1982, se elaboró el material para los cinco primeros años de estudio y en una segunda etapa durante 1984 se desarrolló el material para tres años más constituyéndose los ocho niveles de lectura (Alliende, Condemarín y Milicic, 1991).

La adaptación al Perú fue realizada por Delgado, Escurra y Torres (2005). Posteriormente, se determinó la confiabilidad y validez para las pruebas correspondientes al Primer, Segundo, Tercer, Cuarto, Quinto y Sexto grado de Primaria Forma A. El estudio determinó además normas de corrección y calificación estableciendo percentiles para cada test sobre una muestra de niños pertenecientes a colegios estatales y no estatales (Delgado, Escurra y Torres, 2007). En la presente investigación se usaron las adaptaciones y el análisis psicométrico de las pruebas del Cuarto grado de Primaria (CLP 4-A), Quinto grado de Primaria (CLP 5-A) y Sexto grado de Primaria (CLP 6-A).

La prueba evalúa las áreas de la palabra, la frase, texto simple y texto complejo. Está dividida en ocho niveles de lectura, los cuales representa el grado escolar en el que el evaluado está estudiando, cada nivel presenta dos formas de aplicación A, y
$\mathrm{B}$, las que podrían aplicarse a manera de pre y post test, pero nunca de manera simultánea. Cada nivel está construido de modo que presente una dificultad creciente desde el punto de vista lingüístico, produciéndose paralelamente un incremento de la dificultad de la comprensión. Cada nivel posee a su vez cuatro sub-tests. El puntaje máximo de cada subtests oscila entre los 3 y los 8 puntos dependiendo el nivel de evaluación. En el presente estudio se usó el formato A de cada cuadernillo correspondiente al cuarto, quinto y sexto grados.

Para la administración se entrega a los alumnos el cuadernillo correspondiente al nivel a evaluar y un lápiz. Los alumnos pueden releer los textos y preguntas para mejorar sus respuestas. El tiempo de aplicación es de aproximadamente 45 minutos para cada Forma. Puede ser aplicado de manera individual o colectiva pero en el presente estudio se administró de manera colectiva.

\section{Análisis de datos.}

En primer lugar se calcularon los estadísticos descriptivos (media, moda y desviación estándar) de ambas variables para la muestra total y para cada grupo de edad. La revisión de la distribución de frecuencias de las puntuaciones reveló que las mismas no siguen una distribución normal en ninguno de los grupos de edad. Por lo tanto, se decidió utilizar la prueba $U$ de Mann-Whitney para contrastar las puntuaciones en MT y CL entre ambos grupos de edad. Por otro lado, se realizó la prueba de normalidad Kolmogorov-Smirnov de ambas variables para la muestra total. Sobre la base del resultado de dicha prueba, se calculó la correlación de rangos de Spearman $\left(\mathrm{r}_{\mathrm{s}}\right)$ entre $\mathrm{MT}$ y $\mathrm{Cl}$. El nivel de significación utilizado fue del 0,05.

\section{RESULTADOS}

La puntuación media en MT para la muestra total fue de 8,72, siendo la desviación estándar 6,58, lo que indicaría que la presente muestra presenta una alta dispersión de sus valores. La media para el grupo de 10 años fue de 7,93 y para el de 11 años fue 9,50. En el grupo de 10 años las puntuaciones varían entre 0 y 26 , en tanto que en el grupo de 11 años varían entre 0 y 30 . En ambos grupos la puntuación que corresponde a la moda es 4. Estos datos indican que la puntuación en MT no sigue una distribución normal. En la tabla 2 se presentan los resultados de la prueba de MannWhitney para la comparación de la MT según la edad. Dichos resultados indican que no existe diferencia 
significativa entre los grupos de 10 y 11 años en sus puntuaciones en MT.

Tabla 2. Prueba U de Mann-Whitney de comparación de la memoria de trabajo según edad

\begin{tabular}{ccccc}
\hline Edad & Rango Promedio & $\boldsymbol{U}$ & $\boldsymbol{Z}$ & $\boldsymbol{p}$ \\
\hline 10 años & 57,42 & 1615,00 & $-0,983$ & 0,326 \\
11 años & 63,58 & & & \\
\hline
\end{tabular}

En cuanto a la CL, la puntuación media para la muestra total fue 14,51 y la desviación estándar fue 7,79. La media para el grupo de 10 años fue 9,52 y la del grupo de 11 años fue 19,50. En el grupo de 10 años la puntuación varió de 2 a 19, mientras que en el grupo de 11 años varió de 6 a 32. La moda fue mucho más alta en el grupo de 11 (20) que en el de 10 (8). Estos valores para la moda indican que en ambos grupos, la puntuación en CL no sigue una distribución normal. La tabla 3 muestra los resultados de la prueba de MannWhitney de comparación de la CL entre ambos grupos de edad. En este caso, la diferencia es estadísticamente significativa.

Tabla 3. Prueba U de Mann-Whitney de comparación de la comprensión lectora según edad

\begin{tabular}{ccccc}
\hline Edad & Rango Promedio & $\boldsymbol{U}$ & $\boldsymbol{Z}$ & $\boldsymbol{p}$ \\
\hline 10 años & 38,90 & \multirow{2}{*}{504,00} & $-6,814$ & $<0,001$ \\
11 años & 82,10 & & & \\
\hline
\end{tabular}

La prueba de Kolmogorov-Smirnov arrojó un valor de 2,12 $(p<0,001)$ para MT y de 1,66 $(p=9,08)$ para $\mathrm{CL}$, en ambos casos a nivel de la muestra total. Las correlaciones Spearman entre ambas variables fueron las siguientes. En la muestra total, se obtuvo Rho $=0,25$ $(p=0,007)$, en el grupo de 10 años, la Rho fue de $0,105(p=0,42)$ y en el grupo de 11 , la correlación fue de Rho=0,382 $(p=0,03)$. Según Castro y Galindo (2009), las dos primeras correlaciones mencionadas se clasificarían como bajas, mientras que la última se clasificaría como de intensidad media. Como puede verse, sólo las correlaciones de la muestra total y del grupo de 11 años resultaron significativas; sin embargo, esta evidencia es suficiente para concluir que la MT y la comprensión lectora están relacionadas.

\section{DISCUSIÓN}

La correlación hallada entre MT y CL se resume en que mejores rendimientos en la primera están asociados a mejores desempeños en la segunda. Este resultado confirma estudios anteriormente realizados (e. g., Fernández \& García-Madruga, 2008; Hulme \&
Mackenzie, 1994; Pérez, 2013; Yaringaño, 2009) en distintas poblaciones y utilizando combinaciones de instrumentos distintas de la empleada en el presente estudio. En conjunto, estos hallazgos demuestran la consistencia de la relación entre MT y CL a lo largo de diversas poblaciones, grupos etarios y técnicas e instrumentos específicos para evaluar ambas variables. Al comparar los grupos de edad, se halló que en el grupo de 10 años no se comprueba la la relación entre la MT y la CL, por lo que al parecer a esta edad el rendimiento en MT no necesariamente se asocia con el rendimiento en CL, pero al analizar la relación entre estas variables en niños de 11 años si se encuentra una estrecha relación entre ambas. Este hallazgo requiere un análisis más detallado ya que constituye una excepción a la regla. Por ejemplo, Hulme (Hulme y Mackenzie, 1994) investigó en niños agrupados en dos niveles de edad: el grupo más joven conformado por niños de siete a ocho años y el grupo mayor conformado por niños de nueve y diez años. Hulme encontró correlaciones en ambos grupos obteniendo una correlación ligeramente mayor para el grupo de niños más jóvenes, contrariamente a lo hallado en el presente estudio. Las variaciones en la magnitud de las correlaciones pueden ser lo suficientemente grandes como para que, en algunos casos, estas no resulten significativas para determinados sub-grupos de la población. Debe tenerse en cuenta, igualmente, que distintos instrumentos pueden producir resultados ligeramente diferentes; sin embargo, lo importante es la relativa consistencia de los hallazgos que confirman la relación entre MT y CL.

Las puntuaciones observadas en MT no siguen una distribución normal, siendo predominantes las puntuaciones más bien bajas, aunque notándose una amplia dispersión en dichas puntuaciones. Probablemente, este resultado refleja una tendencia en el progresivo desarrollo de la MT con la edad (e. g., Zald y Iacono, 1998). Este análisis podría confirmarse con los resultados de Fernández \& García-Madruga (2008), quienes observaron que el grupo que evidencia mejores resultados es el de los participantes de 16 años en comparación con los participantes de 13 años. En el presente estudio no se halló diferencia entre los grupos de 10 y 11 años en el rendimiento en MT, pero esto se debe probablemente sólo a la cercanía de estas edades. La literatura reunida hasta el momento nos aproxima a la reflexión de que se puede estimular la MT desde que el niño está en etapa pre-escolar, pero la dosificación de la misma debe ser gradual, explotándose durante todo el periodo escolar del niño. Al respecto un buen punto de partida podrían constituir los estudios 
que Hulme y Mackenzie (1994), quienes proponen un trabajo remedial para la MT a realizarse en aula durante 10 días por 10 minutos cada día. Otro aspecto que se debe considerar, porque apoya el hecho de incorporar una estimulación de la MT desde los primeros años de educación, es que el rendimiento de la memoria operativa es un buen predictor del éxito en el aprendizaje (Ocampo y Sierra, 2014); por lo tanto, su entrenamiento podría no sólo prevenir dificultades, sino estimular y generar un excelente recurso que favorecería el desarrollo de la CL.

El cómo se explotaría esta función también es importante, ya que diversos estudios han demostrado que la capacidad de la MT se ve fortalecida cuando el material es acompañado con material visual (Hulme y Mackenzie, 1994) y si a ello se agrega un ambiente positivo y dinámico, como la presencia de un educador controlado en sus emociones, creativo en las estrategias que usa, comprensivo y capacitado en las características del funcionamiento cerebral del aprendiz, las mejores condiciones emocionales y neurológicas para el aprendizaje se encontrarán dispuestas (Saavedra, 2001).

Respecto de la CL, la comparación de los grupos de 10 y 11 años indica una diferencia estadísticamente significa con puntuaciones más altas en el grupo de 11 años. Los resultados obtenidos en la presente investigación pueden relacionarse a otros estudios realizados en diversos contextos culturales. Por ejemplo, Fernández y García-Madruga (2008) hallaron incrementos en la CL en función de la edad en estudiantes de secundaria de Madrid. Resultados similares han sido obtenidos en el contexto peruano. Por ejemplo, el Ministerio de Educación del Perú (2015) realizó estudios durante los años 2007 y 2012 en una muestra de 3,031 niños pertenecientes al nivel primaria (desde primero a sexto grado de primaria), los cuales permitieron observar un avance progresivo de un año a otro en los niños evaluados. Si bien el análisis se realizó entre grados, los niños evaluados durante más de tres años fueron los mismos, observándose el progreso de una edad a otra en el mismo niño y la diferencia de rendimiento ascendente entre los grupos evaluados. En el estudio del MINEDU es de importancia destacar dos puntos; por un lado, se menciona la influencia del rol del padre en el éxito que el niño pueda alcanzar en su educación, y por otro, se resalta el papel del docente y la infraestructura como agentes influyentes de éxito en CL. Yaringaño (2009) también encontró diferencias significativas en el comportamiento de la CL en grupos de niños de diferentes edades. Como en el caso del estudio del MINEDU, Yaringaño comparó grados de estudio. Halló un mejor rendimiento en el grupo de sexto grado (edad promedio 11,04 años) que en el de quinto grado (edad promedio de los niños: 9,96 años).

Los resultados aquí reportados indican un potencial a partir de la estimulación de la MT como un medio para incrementar la CL. Respecto específicamente de la realidad peruana, se puede destacar que según el Informe Pisa 2012, el Perú ha conseguido un notable avance de 5.2 puntos anuales en el rubro de comprensión lectora siendo el país que más ha mejorado dentro de América Latina, y lo más rescatable a considerar es que el avance, aunque pequeño, ha sido progresivo en cada una de las evaluaciones en la que Perú ha intervenido. Si bien este avance sostenido no significa aún que el Perú dejó de ser uno de los países con más bajo resultado, no impide suponer un avance que requiere seguir siendo implementado (Cuarto Poder, 2013). Asimismo, los informes presentados por el Ministerio de Educación reflejan una mejora en todos los departamentos del país. La mejora se traduce en el avance sostenido de $33 \%$ de rendimiento satisfactorio obtenido en 2013 a un $43.5 \%$ obtenido en 2014 (Ministerio de Educación [MINEDU], 2014). Todo ello, sin duda, estaría asociado a las muchas políticas que se vienen implementando dentro de la educación escolar peruana. Sin embargo, es importante considerar que al ser la MT la instancia donde se desarrollan los principales procesos para la comprensión, y que se puede contar con ella desde la primera infancia, sería interesante proponer su estimulación directa desde los primeros años de educación generando una nueva estrategia para el mejoramiento de la CL.

\section{REFERENCIAS BIBLIOGRAFICAS}

Alliende, F., Condemarín, M. \& Milicic, N. (1991). Prueba CLP Formas Paralelas. Manual para la aplicación de la Prueba de Comprensión Lectora de Complejidad Lingüistica Progresiva: 8 Niveles de Lectura. Santiago de Chile: Ediciones Universidad Católica de Chile.

Alonso, J. (1992). Leer, comprender y Pensar: Nuevas estrategias y técnicas de evaluación. Madrid: CIDE.

Argüello, D., Jácome, K., Martínez, L, Pineda, G. \& Conde, C. (2013). Memoria de trabajo en niños escolarizados: Efecto de intervalos de presentación y distractores en la prueba computarizada Memonum. Avances en Psicología Latinoamericana, 31 (2), 310323. Recuperado de http://www.scielo.org.co/pdf/ apl/v31n2/v31n2a02

Baddeley, A. D., \& Hitch, G. (1974). Working 
Memory. Psychology of Learning and Motivation, 8, 47-89. DOI: http://dx.doi.org/10.1016/S00797421(08)60452-1

Bruning, R., Schraw, G., Norby, M. \& Ronning, R. (2007). Psicología cognitiva y de la instrucción. Madrid: Pearson Educación SA.

Caicedo, H. (2012). Neuroaprendizaje: Una propuesta educativa. Colombia: Ediciones de la U. Carriedo, N. \& Rucián, M. (2009). Adaptación para niños de la prueba de amplitud lectora de Daneman y Carpenter. Infancia y Aprendizaje. Journal for the Stydy of Education and Development, 32(3), 499465. Recuperado de http://www.tandfonline.com/doi/ abs/10.1174/021037009788964079

Castro, J. \& Galindo, P. (2000). Estadística multivariante. Análisis de correlaciones. Salamanca, España: Ediciones Amaru.

Cuarto Poder. (2013, 8 de diciembre). Las lecciones de la Prueba Pisa Perú. Lima: AmericaTV.

Daneman, M. \& Carpenter, P. (1980). Individual differences in Morking Memory and Reading. Journal of Verbal Learning and Verbal Behavior, 19, 450-466. Recuperado de: https://re5120.files. wordpress.com/2010/05/daneman_carpenter_80.pdf Delgado, A., Escurra, L. \& Torres, W. (2007). Pruebas Psicopedagógicas Adaptadas en Percepción, Razonamiento Matemático, Comprensión Lectora y Atención. Lima: Hozlo.

Elosúa, M., Gutiérrez, F., García, J., Luque, J. \& Gárate, M. (1996). Adaptación Española del "Reading Span Test" de Daneman y Carpenter. Psicothema, 8 (2), 383-395. Recuperado de: http://www.psicothema. com/pdf/37.pdf

Fernández, T. \& García-Madruga, J. (2008). Memoria operativa, comprensión lectora y razonamiento en la educación secundaria. Anuario de Psicología, 39, 133-157. Recuperado de: http://www.redalyc.org/ articulo.oa?id=97017401013

Fernández, J. \& Fraga, I. (2004). Procesos psicológicos básicos II. Manual de prácticas de memoria y lenguaje. Ciudada de México: Pirámide.

García, J., Elosúa, M., Gutierrez, F., Luque, J. \& Gárate, M. (1999). Comprensión lectora y memoria operativa. Aspectos Evolutivos. Buenos Aires: Paidós.

Gómez-Veiga, I., Vila, J., García-Madruga, J., Contreras, A. \& Elosúa M. (2013), Comprensión Lectora y procesos ejecutivos de la Memoria Operativa. Psicología Educativa, 19 (2), 103-111.

Hulme, Ch. \& Mackenzie, S. (1994). Dificultades graves en el aprendizaje. El papel de la memoria de trabajo. Barcelona: Ariel.
Inga, M. (2008). Investigación del papel de la memoria operativa, la inferencia y la competencia gramatical en la comprensión lectora. Investigación Educativa, 12(22), 141-170. Recuperado de: http:// revistasinvestigacion.unmsm.edu.pe/index.php/educa/ article/view/3877/3102

Kintsch, W. \& van Dijk, T. A. (1978). Toward a model of text comprehension and production. Psychological Review, 85, 363-394.

Ministerio de Educación. (2014). Resultados de la Evaluación Censal de Estudiantes 2014. (ECE 2014). Lima: Ministerio de Educación. Recuperado de: http://umc.minedu.gob.pe/wp-content/uploads/2015/02/ ECE-2014-Web-270215-27febv2.pdf

Ministerio de Educación. (2015). Aprendizajes de Primero a sexto de Primaria en Lectura y Matemática. Un estudio longitudinal en instituciones educativas estatales de Lima Metropolitana. Lima: Ministerio de Educación. Recuperado de :http:// umc.minedu.gob.pe/wp-content/uploads/2015/08/ LIBRO+LONGITUDINAL+PARA+WEB BAJA.pdf Miranda, A., Vidal-Abarca, E. \& Soriano, M. (2011). Evaluación e intervención psicoeducativa en dificultades de aprendizaje. Madrid: Pirámide.

Ocampo, T. \& Sierra, Ó. (2014). Análisis del funcionamiento de la memoria operativa en niños con trastornos en el aprendizaje. Acta Colombiana de Psicología, 17, 81-90. Recuperado de http:// ww.redalyc.org/articulo.oa?id=79832492009

Pérez, Y. (2013). Relación entre memoria de trabajo y lenguaje comprensivo en niños de 8 a 11 años de edad. Revista Psicológica Herediana, 5 (1-2), 9- 22.

Prada, E., Pineda, G. Mejìa, M. \& Conde, C. (2010). Prueba computarizada Memonum: efecto de intervalos y distractores sobre la memoria de trabajo en mujeres mayores de 50 años. Universitas Psychologica, 9 (3), 893-906.

Saavedra, M. (2001). Aprendizaje basado en el cerebro. Revista de Psicología, 10, 141-150.

Smith, E. (2008). Procesos cognitivos: modelos y bases neurales. Madrid: Pearson.

Tristán-López, A. (2007). Tablas de Validez de Contenido (TVC). San Luis de Potosi: Instituto de Evaluación e Ingeniería Avanzada, S.C. Recuperado de http://www.itsescarcega.edu.mx/documentosdesacad/ Curso\%20Taller/TABLAS 1.PDF

Yaringaño, J. (2009). Relación entre la Memoria Auditiva Inmediata y la Comprensión Lectora, en alumnos de quinto y Sexto de primaria de Lima y Huarochirí. Revista IIPSI, 12 (2), 147-165.

Zald, D. H. \& Iacono, W. G. (1998). The development of spatial working memory abilities. Developmental Neuropsychology, 14, 563-578. 